\title{
Editorial
}

\section{THE WORLD HEALTH ORGANIZATION AND LEPROSY}

The Report of the Director General to the 30th World Health Assembly (1977) is a substantial document extending to 20 pages and covering the wide range of concern which WHO now has with leprosy control and research. This is surely an appropriate occasion to appreciate the services WHO has rendered in the fight against leprosy during the first generation of its existence.

It is interesting to look back over the past 30 years and notice how far leprosy has figured on the Agenda of previous World Health Assemblies. The first reference to leprosy appeared in the Report of the Director General to the 3rd Assembly (1950) and consisted of a short paragraph regarding the appointment of a leprosy consultant in Ethiopia. During the next 10 years references to leprosy continue to be meagre. In many quarters leprosy was still regarded as a highly specialized subject, outside the range of government health planning, and still very much the concern of voluntary agencies and dedicated individuals. Although change was on the way, the attitude to leprosy in some instances was not merely apathetic but was actively negative, regarding leprosy as something to be ashamed of, a skeleton in the cupboard not to be exposed to the light of world publicity. All honour therefore to Ethiopia, Sri Lanka and Burma who opened themselves to the influence of WHO at an early stage and became the scene of major developments in leprosy research and control.

The WHO Leprosy Secretariat was established in 1958. The task confronting them was formidable. By definition, WHO was concerned primarily with health. In relation to a neglected and emotive sphere such as leprosy, there could be no speedy and co-ordinated programme of eradication on a global scale. WHO is an international and not a supranational organization and has no authority other than that entrusted to the Director General by Member States. Lacking any authority, WHO could only stimulate concern and action by suggestion, advice and example. Nevertheless, in the 1950s there was considerable activity in WHO behind the scenes. At first, the Leprosy Secretariat were clearly feeling their way, but their activities indicate a pragmatic approach which time has amply endorsed. From early reports and publications it is apparent that the task of WHO in relation to leprosy was seen to include the establishment and publication of the facts, encouraging and drawing attention to points of growth; broadening isolationist attitudes by facilitating the movement of leprologists and government medical administrators; organizing international conferences and seminars; giving very positive support to reasearch projects relevant to health, and to training at all levels; and actually engaging where invited in specific field projects. Once developed this policy was pursued with skill and determination. WHO's involvement with malaria, tuberculosis and other infective diseases meant that 
leprosy could be seen in its wider context, and expertise and experience gained in other directions could be applied to leprosy. The benefits of this have been obvious, helping the building up of a world approach from an impregnable situation of knowledge in the wider context of health.

\section{The WHO Expert Committee on Leprosy}

A basis of expert judgment in relation to leprosy was the first priority. This led to the formation of the first WHO Expert Committee on Leprosy, which met in 1952, its members carefully selected on an international basis. This Panel concerned itself with: leprosy control and treatment, the contagiousness of different forms of leprosy; prophylaxis by BCG; the standardization of the lepromin test and the classification of the different forms of leprosy. The Committee met subsequently at intervals of approximately five years, the latest being the 5th Meeting in October 1976. The reports of these Meetings have been of the highest significance, giving guidance and stimulating discussion which have been of great value both to WHO itself and to governments and workers generally. If WHO had done nothing beyond this, its contribution to the understanding and control of leprosy would have been considerable.

\section{Epidemiology and Control}

The International Leprosy Congress at Madrid in 1953 became a watershed in the outlook for leprosy treatment by its endorsement of domiciliary chemotherapy with dapsone as a routine procedure. The expansion of WHO involvement in leprosy control dates from that time, with its emphasis on epidemiological surveys, out-patient treatment with dapsone and sustained field studies. All the same, the reports of the Director General continued to be brief into the 1960s but rapidly expanded during the second half of that decade.

\section{(a) ADVISORY SER VICES}

The direct involvement of WHO in national leprosy situations began with the request from Ethiopia in 1950 for an Adviser in planning leprosy control, the first of many such requests, response to which was limited only by the shortage of available specialists. The presence of a WHO Adviser meant that international thought was brought to bear on the local problem and a door opened for international aid in practical measures. Many leprosy programmes were initiated as a result of this primary response on the part of WHO, and the benefit was mutual, WHO building up an increasing breadth of experience from which other nations were destined to benefit in their turn. In 1964, technical advice and guidance was given to 35 countries in planning their leprosy control programmes.

An important aspect of this was the organising by WHO of regional seminars and conferences where technical advances in leprosy were publicised, health ministries could share problems, discover common ground, the more dilatory in leprosy control be stimulated by the example of others. Regional events of this nature have been held in many parts of the world. 


\section{(b) EPIDEMIOLOGICAL STUDIES}

The need for careful epidemiological studies to establish the prevalence, incidence and trend of leprosy, has been a consistent emphasis of WHO, and its influence in this sphere has been considerable, establishing and demonstrating standards of work and analysis. The importance of this is apparent from the numerous published findings of leprosy surveys in which the help of WHO is acknowledged, two of them in this issue of Leprosy Review. In 1960 a WHO Advisory Team started work in Africa "to assist countries in determining the prevalence, trend and endemicity and frequency of deformities and disabilities". In the following year field studies were initiated in different parts of the world to evaluate attack rates.

Leprosy survey work poses difficult problems, and the experience gained by WHO in one country often proved useful elsewhere. The successful combination of leprosy with yaws surveys in E. Nigeria led to similar approach in The Gambia, Sierra Leone and Togo. Another example is the combination of leprosy with tuberculosis surveys in Nepal and Upper Volta (1974).

\section{(c) THE PROMOTION OF OUT-PATIENT TREATMENT PROGRAMMES}

It was realised very early that leprosy surveys were positively harmful unless combined with facilities for treatment. WHO did much to publicise DDS therapy and promote out-patient treatment programmes, either through financial aid or direct involvement in field projects, e.g. in Burma, Thailand and Pogiri, India. The involvement of UNICEF in leprosy by providing dapsone for out-patient treatment was another service encouraged by WHO. This began in Nigeria in 1953, and the writer was one of those involved in it. The example there set was extended throughout much of the world, until in 1967, 38 leprosy control projects were being assisted by WHO and UNICEF, and many millions of dapsone tablets were being supplied free of cost. As early as 1964, in projects assisted by WHO and UNICEF, 2,854,197 cases were registered, and 1,826,688 patients were attending.

\section{(d) EVALUATION OF LEPROSY CONTROL PROGRAMMES}

The need for careful evaluation of leprosy control programmes in order to improve quality of work was another principle for which WHO was especially responsible, setting standards which have been widely accepted. In 1973 evaluations of leprosy control programmes were undertaken in Botswana, Central African Republic, Chad, The Gambia, Upper Volta, also Burma and Thailand.

There must now be very few countries where leprosy is endemic who have not benefitted from the many facetted aid of WHO in leprosy control. The 1973 list for instance includes, Bangledesh, The Maldives, Indonesia, Nepal and Sri Lanka. Relationships have not always been easy, but co-operation with WHO has in fact transformed the leprosy situation in many countries.

\section{(e) INTEGRATION OF LEPROSY INTO GENERAL HEALTH SERVICES}

Nigeria was one of the earliest countries to embark on a large domiciliary leprosy control programme, and by the 1950s the leprosy problem in E. Nigeria had shrunk to a point where leprosy workers were already being integrated into the general health services, and their colleagues in general medicine were receiving suitable training in leprosy to equip them to take leprosy into their system. This was known to WHO and reference to such integration as a principle appears in the 
Director General's Report of 1960. Since then, it has figured increasingly in WHO policy, and in some countries, e.g. Nepal, through the active encouragement of WHO the fight against leprosy has been integrated from the start. At the same time, the 1970 Report cautioned against instituting integration without adequate preparation.

\section{The Training of Leprosy Personnel}

The involvement of WHO in national leprosy problems has in general been a short term process, a preparation for the assimilation of leprosy control into the national health programme. The wider training of medical personnel who would have responsibility in this was thus integral to WHO policy from the start, and numerous travelling fellowships were awarded. We at Uzuakoli in Nigeria received a succession of WHO Fellows in the 1950s, certain of whom later became leaders in the campaign in their own countries.

Seminars for the training and orientation of Medical Officers towards leprosy have also been a feature of WHO policy, particularly important where the integration of leprosy into general health services has been under discussion. Early examples were the post-graduate training course in Tokyo in 1961 and the training conference in the Philippines in the same year. The writer recalls a successful orientation seminar for Senior Medical Officers at Katmandu in 1969, which undoubtedly paved the way for later advance in leprosy control in Nepal. The Director General declared in 1973, "The promotion of training of general health personnel is receiving priority attention".

\section{Disability Studies}

An important concern of WHO in the care of patients has been the need for action regarding the disabilities caused by leprosy. Reference to this occurred in the Director General's report in 1959, which stated that $25 \%$ of patients suffer from disabilities, $90 \%$ of which could be prevented in the early stages. The Second Committee in 1959 also made an important statement on this subject. In 1961, WHO was responsible for calling together a Scientific Meeting on Rehabilitation in Leprosy at Vellore, India, notable for the participation of workers in disciplines other than leprology, and important advances followed, not least the encouragement of research outside leprosy institutions. WHO emphasis on leprosy disabilities has been continuous, as is exemplified by the report in this issue of Leprosy Review on disabilities in the New Hebrides.

The Director General in his 1976 report said "Disease orientated medicine needs to be complemented by disability orientated medicine, and it should be realised in every country that the objectives of medicine are not only the prevention and cure of disease but also the restoration of the individual to normal social function".

\section{Research and Publications}

The distinguished role of WHO in leprosy research is so well known as to need only brief reference here. It has covered all aspects of research which have relevance to the understanding and control of the disease, and through research fellowships, grants in aid, and direct involvement in specific projects has 
contributed enormously both to knowledge and to the acceptance of leprosy by governments and research workers alike as a subject of concern and challenge. Positive steps have been taken to promote research in countries where leprosy is endemic. In 1973 WHO co-operated with 42 Institutes in 24 countries in 58 research projects, embracing: epidemiology, leprosy control, biology of $M$. leprae, experimental leprosy, immunology, pathology, experimental and human chemotherapy including chemoprophylaxis and prevention. As the report of the Director General stated, "This is essential work as long as the disease can only be restrained by secondary preventive measures".

The publication of scientific material is an important part of WHO's involvement in research. The Bulletin of WHO and WHO Chronicle have been media of wide distribution and value.

\section{World Statistics of Leprosy}

Yet another service rendered by WHO has been the collection and publication of statistics relating to leprosy on a global scale. The report of the Director General in 1959 included responses to a world wide questionnaire regarding prevalence and registration for treatment. Statistics gathered then gave an estimated total of 10-12 million sufferers, of whom 1,579,532 were registered for treatment. In 1966, out of a total of 11 million estimated cases, 2.8 million were registered, and 1.9 million actually taking treatment. Detailed figures for 1970, collected by Bechelli, gave 10,407,200 as a conservative estimate (Asia 6.5 million, Africa 3.5 million, the Americas 350,000). The 1977 Report gives figures by country for Asia and the Americas. It is invidious here to follow the trend in individual countries. Statistics are often a notoriously unreliable guide to the actual situation, but these are a salutory reminder that leprosy is still a serious problem in many countries.

It is a far cry from the first almost tentative reference to leprosy on the part of WHO in 1950 to the major report in 1977, over 100 times as long. This is the measure of the remarkable change in world opinion which has taken place in recent years, and to which WHO has contributed so profoundly. The miracle had already happened by 1974, when the World Health Assembly, in Resolution WHA $27 / 58$ recommended that Member States should strengthen their leprosy control measures by calling upon all available sources of co-operation. This resolution not only implied that Health Ministries everywhere should be taking leprosy seriously, but also openly encouraged them to seek the cooperation of voluntary agencies, a breakthrough in official attitudes indicative of real concern. From this point it was a small step to the inclusion of leprosy in the 6 diseases selected for the WHO Special Programme for Research and Training in Tropical Diseases, and the development of IMMLEP and THELEP. It is impossible to exaggerate the part played by WHO in this transformation, combining, as it has, a sustained insistence on the need for serious attention to leprosy, a scientific approach in dealing with it, and a humane attitude to patients. The stage is now becoming set for a global anti-leprosy strategy in which leprosy is fully integrated with general medicine, but its seriousness as a leading disabling disease in many countries is equally recognised. We can but express our gratitude to our colleagues in WHO for their great services to sufferers from leprosy during this first generation of the life of WHO. 